\title{
Quality Analysis of Milk in Kathmandu Valley
}

\section{Astha Parajuli ${ }^{1}$, Prasiddhi Rimal ${ }^{1}$, Rujisha Maharjan ${ }^{1}$, Richa Chaudhary ${ }^{1}$, Shashi Bhushan Chaturwedi $^{{ }^{*}}$}

${ }^{1}$ Department of Microbiology, DAV College of Science and Humanities, Lalitpur, Nepal

*Corresponding author: Shashi Bhushan Chaturwedi, Department of Microbiology, DAV College of Science and Humanities, Lalitpur, Nepal; E-mail: sbhushan2016@gmail.com

\begin{abstract}
Objectives: This study was carried out to evaluate physiochemical, adulteration and microbial quality of milk sold in Kathmandu valley.

Methods: The total of 20 milk samples randomly collected from different places of the valley including 10 pasteurized milk sample and 10 were raw milk sample, were processed for physiochemical and microbiological parameters.
\end{abstract}

Results: The laboratory analysis revealed that the pasteurized samples has less mesophilic count as well as coliform count than raw milk samples. About 55\% milk samples showed neutralizer test positive and $10 \%$ of milk samples were found to be positive for sugar test. However, none of the samples were found to contain starch as an adulterant. The average fat content of milk samples was $3 \%$. Fat percent was significantly different among different sources of sampling points. The highest milk fat content value was recorded at Pulchowk (3.7\%). The average SNF was 7\% in which the pasteurized sample had the highest average SNF (7.3\%) and the raw milk had lowest average SNF $(6.8 \%)$.

Conclusion: The significant variation in the physiochemical properties and microbial properties of the milk samples showed that people should be conscious about the consumption of market milk.

Key words: Fat, SNF, acidity, coliform count, adulteration

\section{INTRODUCTION}

Milk is defined to be the lacteal secretion, practically free from colostrums, obtained by the complete milking of one or more healthy cows, five days after and 15 days before parturition, which contains not less than 8.5 percent milk solids-not-fat and not less than 3.5 percent milk fat (U.S. Public Health Services, 1965).

When milk is drawn from the udder of a healthy animal, milk contains organisms from the teat canal. They are mechanically flushed out during milking. Milking under hygienic conditions with strict attention to sanitary practices will result in a product with low bacterial content and good keeping quality. But if maintained under conditions that permit bacterial growth, then the raw milk will develop a clean, sour

Date of Submission: September 11, 2018

Published Online: January 2019 flavor. This is due to fermentation of lactose to lactic acid (Pelczar et al. 2013)

Raw milk is milk that has not been pasteurized, a process of heating liquid foods to decontaminate them for safe drinking. Pasteurizing milk involves exposing milk to high temperatures for a short period of time to destroy all harmful bacteria that might be lurking in the milk.

Due to the fact that milk-borne diseases, chemical and physicalquality of milk are of public health importance, there is a need to screen the milk in informal market for the sake of consumer health protection (Mansouri \& Sharifi, 2013).

The main purpose of this study is to assess quality of milk in Kathmandu valley.

Date of Acceptance: December 7, 2018

DOI: http:/ / doi.org/10.3126/tujm.v5i0.22295 


\section{MATERIALS AND METHODS}

The milk samples were collected from Kathmandu valley, 10 pasteurized samples and 10 raw milk samples. A cross-sectional study was carried out in the department of Microbiology, D.A.V. College of Science and Humanities from January to May, 2018. All of the collected milk samples were placed for physiochemical analysis (fat percentage, total solid and solid not fat), adulteration test (starch, neutralizer, table sugar) and microbial analysis(bacterial count, coliform count) by following the standard laboratory manual as suggested by Marth (1978).

\section{RESULTS}

As shown in table 1, physiochemical analysis of the milk samples revealed that half of the pasteurized milk samples contained less percentage of fat whereas most of the raw milk samples contained good percentage of fat (Table 1).

Table 1: Physiochemical analysis of raw and pasteurized milk

\begin{tabular}{lccccccc}
\hline \multirow{2}{*}{ Samples(milk) } & \multicolumn{2}{c}{ Fat } & \multicolumn{2}{c}{ TS } & \multicolumn{2}{c}{ SNF } & Total \\
\cline { 2 - 9 } & $\geq 3 \%$ & $<3 \%$ & $\geq 12.5 \%$ & $<12.5 \%$ & $\geq 8 \%$ & $<8$ & \\
\hline Pasteurized & $5(50 \%)$ & $5(50 \%)$ & - & $10(100 \%)$ & - & $10(100 \%)$ & 10 \\
Raw & $8(80 \%)$ & $2(20 \%)$ & - & $10(100 \%)$ & $1(10 \%)$ & $9(90 \%)$ & 10 \\
\hline
\end{tabular}

The milk samples were tested for adultarants such as starch, neutralizer and table sugar where neutralizer was found commonly used adultrant in pasteurized milk than raw milk. (Table 2).

Table 2: Adulteration test of milk for starch, neutralizer and table sugar

\begin{tabular}{lcccc}
\hline \multirow{2}{*}{ Adulterant } & \multicolumn{2}{c}{ Pasteurized milk } & \multicolumn{2}{c}{ Raw milk } \\
\cline { 2 - 5 } & Positive & Negative & Positive & Negative \\
\hline Starch & - & $10(100 \%)$ & - & $10(100 \%)$ \\
Neutralizer & $7(35 \%)$ & $3(30 \%)$ & $4(40 \%)$ & $6(60 \%)$ \\
Table sugar & $2(10 \%)$ & $8(80 \%)$ & - & $10(100 \%)$ \\
\hline Total & & 10 & & 10 \\
\hline
\end{tabular}

Among the tested milk, pasteurized milk showed 50\% mesophilic count $\left(\leq 10^{5}\right)$ whereasonly $25 \%$ in case of raw milk. Presence of coliforms inraw milk was $40 \%$ while only $20 \%$ in pasteurised milk (Table 3 ).

Table 3: Microbial analysis of milk samples

\begin{tabular}{lccccc}
\hline \multirow{2}{*}{ Samples(milk) } & \multicolumn{2}{c}{ Samples with total mesophilic count } & \multicolumn{2}{c}{ Coliform count } & Total \\
\cline { 2 - 6 } & $\leq 10^{5}(\mathrm{cfu} / \mathrm{ml})$ & $>10^{5}(\mathrm{cfu} / \mathrm{ml})$ & Presence & Absence & \\
\hline Pasteurized & $10(100 \%)$ & - & $4(40 \%)$ & $6(60 \%)$ & 10 \\
Raw & $5(50 \%)$ & $5(50 \%)$ & $8(80 \%)$ & $2(20 \%)$ & 10 \\
\hline
\end{tabular}

Among the coliform, E. coli was found to be most

Enterobacter spp. and Citrobacter spp. in both sample. predominant organism followed by Klebsiella spp.,

Table 4: Distribution of coliform among samples

\begin{tabular}{lcccc}
\hline Sample & \multicolumn{2}{c}{ Pasteurized milk samples } & \multicolumn{2}{c}{ Raw milk samples } \\
\hline & No. & $\%$ & 5 & $\%$ \\
E.coli & 2 & 20 & - & 50 \\
Klebsiella spp. & - & - & - & 10 \\
Enterobacter spp. & 1 & -10 & 1 & - \\
Citrobacter spp. & - & & - & 10 \\
\hline Total sample & & 10 &
\end{tabular}




\section{DISCUSSION}

National Dairy Development Corporation, Nepal recommended a minimum of $3 \%$ fat and our study showed $3 \%$ as an average fat content of milk samples of Kathmandu Valley unlike the study showed by Teklemickeal (2012) and Janstora et al. (2010) who reported $3.86 \%$ and $3.79 \%$ of fat content, respectively. The fat content was significantly affected by the factor such as feed, parity, and stage of lactation. The average SNF of milk samples tested was found to be $7 \%$. The SNF content of milk in this study is less than the finding of Debebe (2010) who reported a minimum $(8.3 \pm 0.30)$ and maximum $(8.7 \pm 0.36)$. According to NDDB, the SNF of milk should be $8 \%$. The low SNF of the samples could have been attributed to a variety of factors including the feed, genetics, season of the year, stage of lactation and disease. The average total solid (TS) content of milk was found to be $10 \%$. This value is less than the finding of Tekelemichael (2012) who reported TS of $12.58 \%$. According to European Union, a recognized quality standard for total solids content of cow milk should not to be less than $12.5 \%$. The variation could be due to difference in breed, feeding and management practices which have important effect on milk composition quality.

In this study, $55 \%$ of the tested milk samples were found to be adulterated with soda whereas among $10 \%$ of the milk sample with table sugar. The added percentage of soda as an adulterant was found to be more than that reported by Bastola, 2016. Soda and table sugar is commonly used as an adulterant to increase the SNF content of milk. Starch was not found to be used as an adulterant in this study as well as in the study by Bastola, 2016. It may be because as starch is expensive, difficult to be homogenized and can be detected and discovered by the consumer.

The study showed the average total mesophilic count of milk samples of Kathmandu valley was in the range of $10^{5}$ bacterial colony forming unit per $\mathrm{ml}$ of milk. From our study, $60 \%$ of the total sample showed coliform which is more than the findings of Nahas et al. (2015) who found $55 \%$ coliform. The higher coliform count observed in the current study might be attributed to the initial contamination of the milk through the milkers, milk containers and milking environment, improper handling, storage and transport facilities.
In previous study by Ali (2006) on pasteurized milk, $2.6 \%$ E. coli and 1.3\% Enterobacter spp. were detected. Similarly, this study showed $30 \%$ E. coli and $20 \%$ Enterobacter spp. which is higher than the previous study. In case of Klebsiella spp.and Citrobacter spp. the finding is similar with our study. In this study, 50\% of the raw milk samples were found to be contaminated with E. coli which was less than that reported by Nahas et al. (2015) who found 55\% milk samples contaminated with E. coli. In a study by Kaloianov and Gogov (1977) most encountered coliforms were Citrobacter (35\%), Enterobacter (29.8\%), Klebsiella (23.9\%) and E. coli (11.3\%) which is much higher than our study. The higher coliform count observed in this study may be due to poor hygiene of farm, the water used while milking and lack of knowledge of hygiene in farmers. Since it is not practical to produce milk that is always free of coliforms, even at high level of hygienic condition; their presence in raw milk to a certain extent may be tolerated. The presence of coliforms in pasteurized milk sample may be due to defective pasteurization, adulteration of pasteurized milk with raw milk and unsanitary handling.

\section{CONCLUSION}

The physiochemical properties of both milk samples should be maintained within the standard limits. To control the microbial contamination in raw as well as pasteurized milk the hygienic condition should be maintained. It is concluded that routine analysis of milk should be done regularly which helps to enhance their quality.

\section{ACKNOWLEDGEMENTS}

We would like to express our heartfelt gratitude to the entire team of Microbiology Department, DAV College, who made available every materials and place required for our study.

\section{CONFLICT OF INTEREST}

The authors declare no conflict of interest.

\section{REFERENCES}

Asamineu T and Eyassu S (2010). Microbial quality of raw cow's milk collected from farmers and dairy cooperatives in Bahir Dar Zuria and Mecha district, Ethiopia. Agricultural and Biological Journal of North America 2(1): 29-33.

Debebe W (2010). Physicochemical properties and 
safety of street-vended milk in and aroundAddis Ababa city (Kotebe, Bishoftu and Chancho), M.Sc. (Agriculture) Thesis. Haramaya University, Ethiopia.

Manandhar S and Sharma S (2013). Practical Approach to Microbiology. National Book Center Pvt. Ltd. pp:245-250.

Marth EH (1978). Standard Methods for the Examinations of Dairy Products. American Public Health Association, Washington, DC. pp:416.

Mansouri-Najandi L and Sharifi HR (2013). Quality of raw milk in Kerman province.

O'Connor CB (1994). Rural Dairy Technology. ILRI
Training Manual No. 1. International Livestock Research Institute (ILRI), Addis Ababa, Ethiopia. pp:133.

Pelczar MJ, Chan E and Krieg N (2013). Microbiology. McGraw Hill Education(India) Private limited, pp:620

Teklemichael T (2012). Quality and Safety of Raw and Pasteurized Cow Milk Produced and Marketed in Dire Dawa Town, M.Sc.Thesis.Haramaya University, Ethiopia.

Walstra P, Geurts TJ, Noomen A, Jellema A and Van Boekel MAJS (1999). Dairy Technology: Principles of Milk Properties and Processes. $1^{\text {st }}$ edition. New York: Marcel Dekker pp:149-170. 